\title{
Sistem Pembibitan PT. Agrowisata Porlak Parna Berbasis Web
}

\section{JOICE ANGELINA PURBA, JURMIDA PULUNGAN, MARDI TURNIP, ADVENT TORAS MARBUN}

Fakultas Teknologi dan Ilmu Komputer Universitas Prima Indonesia

Email: marditurnip@unprimdn.ac.id*

Received 1 November 2020 | Revised 15 November 2020 | Accepted 30 November 2020

\section{ABSTRAK}

PT. Agrowisata Porlak Parna mempunyai program kegiatan penyediaan bibit dan menyalurkan bibit untuk melestarikan kawasan di sekitar danau toba. Namun pengolahan dan penyaluran data bibit mengalami kesulitan Karena sistem yang terdapat pada perusahaan masih menggunakan sistem konvensional. Untuk itu perlu dirancang sistem pembibitan dalam bentuk website dengan PHP digunakan sebagai bahasa pemrograman, DBMS MySQL sebagai database pada model waterfall. Rancangan tersebut menghasilkan sistem pembibitan yang memudahkan admin dalam mengolah data bibit dan pengadopsi dapat mengetahui perkembangan bibit sehingga membantu meringankan pekerjaan pegawai dan meningkatkan kinerja yang baik terhadap perusahaan.

Kata kunci: Sistem Pembibitan, Web, PHP, DBMS MySQL, Waterfall

\begin{abstract}
PT. Porlak Parna Agrotourism has a program of providing seeds and distributing seeds to preserve the area around Lake Toba. However, the processing and distribution of seed data experienced difficulties because the system contained in the company was still using a conventional system. For this reason, it is necessary to design a nursery system. In the form of a website with PHP used as a programming language, DBMS MYSQL as a database in the waterfall model. The design produces a nursery system that makes it easier for admins to process seed data and adopters can find out the development of seedlings so as to help ease the work of employees and improve good performance for the company.
\end{abstract}

Keywords: Nursery System, Web, PHP, MySQL DBMS, Waterfall 


\section{PENDAHULUAN}

Teknologi informasi saat ini telah maju dan berkembang sangat pesat didalam berbagai bidang terutama ilmu pengetahuan, oleh karena itu dengan adanya komputer dapat mempermudah kita dalam melakukan pengolahan data menjadi sebuah informasi. (Turnip, 2018). PT. Agrowisata Porlak Parna adalah perusahaan yang bergerak di bidang pariwisata sektor pertanian dan perkebunan di Kawasan Danau Toba, Kabupaten Samosir, provinsi Sumatera Utara. Perusahaan memiliki program penyediaan dan penyaluran bibit untuk melestarikan kawasan di sekitar Danau Toba. Selain menetapkan visi perusahaan, Memanfaatkan Teknologi Informasi juga merupakan hal yang penting untuk keberhasilan suatu bisnis (Ziraba, 2018). Sistem informasi merupakan sebuah gabungan pemanfaatan teknologi informasi dan kegiatan manusia atas serangkaian prosedur yang disepakati (Pamoragung, 2006) biasanya digunakan untuk mendukung manajemen dan operasi (Ramdhani, 2013). Dengan melakukan teknologi, dapat mempercepat pekerjaan secara sistematis (Rusli, 2018). Namun yang menjadi permasalahan adalah Sistem pembibitan masih menggunakan sistem konvensional. Proses pendaftaran mitra sebagai penyedia bibit membutuhkan waktu yang lama dan bertatap muka. Rekap data bibit dan membuat laporan bibit masih menggunakan alat tulis sehingga Kesalahan mungkin saja terjadi dalam proses pengolahan data. Oleh karena itu bisa menyebabkan kesalahan dalam mendistribusikan bibit. (Loveri, 2007).

Penelitian yang dilakukan oleh (Sapnado, 2020) memiliki judul Sistem Informasi Penjualan Bibit Tanaman berbasis Web menggunakan QRCODE di Toko Lana Sumberan Salaman. Peneliti menghasilkan sistem informasi yang menggunakan QRCODE sehingga mempermudah pencarian informasi mengenai jenis bibit yang dijual, dapat digunakan untuk transaksi penjualan bibit secara online tanpa harus datang ke tokonya, tapi sistem pembayaran masih manual. Untuk merancang sistem tersebut menggunakan Unified Modeling Language (UML).

Kesimpulan yang dapat diambil dari penelitian tersebut bahwa dengan menggunakan sistem barcode calon pembeli dapat dengan mudah mengetahui informasi penjualan bibit sehingga mempermudah terjadinya proses transaksi penjualan bibit. Penelitian ini memiliki perbedaan dengan penelitian sebelumnya karena studi kasusnya di PT. Agrowisata Porlak Parna, fitur yang tersedia yaitu informasi tentang bibit (termasuk lahan), form pendaftaran mitra, form pengadopsi serta dilengkapi dengan laporan. Yang kedua transaksi antara penjualan bibit secara online bagi pengadopsi melalui sistem yang dilengkapi dengan fitur pembayaran melalui transfer. Perancangan Sistem ini menggunakan model waterfall.

\section{METODE PENELITIAN}

Metodologi adalah ringkasan dari pengembangan sistem, siklus hidup dalam proyek berorientasi objek, mengidentifikasi tugas dan hasil (Dennis, 2015). Model waterfall adalah perangkat lunak model klasik teknik (Nabil, 2010). Model ini banyak digunakan di proyek pemerintah dan di banyak perusahaan besar (Bahattab, 2015). Model SDLC air terjun (waterfall) dapat disebut sekuensial linier (sequential linier) atau alur hidup klasik (classic life cycle) merupakan salah satu cara mengumpulkan data. (Hariyanto, 2018). Tahap perencanaan, pemodelan, implementasi dan pengujian merupakan bagian dari pengembangan sistem pada model waterfall. 
Dalam mengembangkan sistem tersebut dilakukan secara bertahap-tahap agar menghasilkan sistem yang berkualitas bagus dan tidak terfokus pada tahapan tertentu saja. Tahapantahapan utama dalam melakukan kegiatan penelitian yaitu analisis, desain, pembuatan kode program (coding), pengujian sistem, pemeliharaan dan operasi program. Pada tahap analisis dijelaskan sistem saat ini, masalah dan peluang ditentukan. Rekomendasi umum tentang caranya untuk melakukan perbaikan, peningkatan atau penggantian sistem yang sebelumnya diusulkan. Tujuan pokok pada tahap analisis yaitu agar dimengerti dan dokumen yang dibutuhkan (Susanti, 2016). Dalam menganalisa sistem yang ada peneliti mendapatkan informasi dengan melakukan wawancara. Dalam proses pengolahan dan pembuatan laporan data bibit pada perusahaan masih konvensional dan diarsipkan dalam bentuk file.

Pada rancangan Sistem Informasi merupakan bagian dari tahap-tahapan desain yang bertujuan untuk mendesain sistem baru agar bisa mengatasi masalah perusahaan melalui pemilihan sistem alternatif terbaik (Muntihana, 2017). Peneliti merancang antarmuka program menggunakan aplikasi laravel sebagai perancangan web dan penulisan script php 7.3. peneliti melakukan perancangan tampilan Home Sistem Pembibitan, tampilan login, dashboard mitra, dashboard admin, form pendaftaran pengadopsi, tampilan pembibitan, tampilan daftar mitra, tampilan menu bibit, tampilan tambah bibit, tampilan lokasi pembibitan, tampilan pertumbuhan bibit, tampilan mitra pembibitan, tampilan pemesanan bibit, tampilan form tambah pemesanan, menu jenis bibit, tampilan laporan order laporan mitra.

Pada tahap pembuatan kode program Penulis memasukkan kode-kode dalam bahasa pemograman yang sesuai dengan desain database serta rancangan antar muka, dimana PHP adalah bahasa pemograman yang digunakan untuk pembuatan website (Udi, 2018). Peneliti menggunakan bahasa pemrograman PHP 7.3 untuk menerjemahkan rancangan ke dalam bentuk bahasa yang dimengerti Komputer.

Pengujian Program menggunakan Black box untuk menghasilkan sistem yang sesuai dengan rancangan. Penggunaan Black box berfungsi untuk menguji sistem dapat berjalan atau tidak pada program tersebut (Risdiyansyah, 2018). Google chrome digunakan untuk menjalankan sistem dan mysql sebagai servernya. Pengujian sistem dimulai dari Homepage (menu utama), form login, pendaftaran mitra, pendaftaran pengadopsi, dashboard mitra, dashboard admin, form tambah bibit, pertumbuhan bibit, pemesanan bibit, menu jenis bibit, laporan order, serta laporan data mitra. Pada pengujian sistem, kesalahan-kesalahan yang ditemukan bisa diatasi dan mengadakan perbaikan agar hasil yang diinginkan dapat terwujud secara maksimal.

Operation \& Maintenance merupakan bagian terakhir pada pengembangan model waterfall. Pemeliharaan sistem sangat dibutuhkan terutama pada saat pengembangan, karena yang kita ketahui sistem yang telah dibuat tidak akan selamanya berjalan dengan lancar. Ada saatnya pada saat dioperasikan dapat terjadinya error atau terjadinya pertambahan fiturfitur dikarenakan permintaan dari luar (Dwi, 2019). Pengguna dapat langsung menjalankan atau mengoperasikan software yang telah selesai dibuat. Selain itu, pemeliharaan perlu dilakukan untuk meningkatkan sistem diantaranya memperbaiki kesalahan, implementasi unit sistem, serta peningkatan jasa sesuai kebutuhan baru. 
Alat dan Hardware yang digunakan beserta spesifikasi sebagai berikut: laragon untuk menjalankan database di mysql, Laravel sebagai perancangan web dan penulisan script php 7.3, Web browser yang digunakan Mozilla 4.0 ataupun google chrome, Sistem operasi Microsoft Windows 7, 8 atau Windows 10, Komputer dengan processor Intel(R) Core(TM) Duo CPU T6570 @ 2.10GHz, 956 MB of RAM, Keyboard, mouse dan printer sebagai media input dan output.

Hal pertama yang dilakukan adalah mengisi form pendaftaran. Setelah itu form tersebut di verifikasi dan disetujui admin. Kemudian pengadopsi dapat melakukan pemesanan bibit dan pesanan tersebut akan diproses.

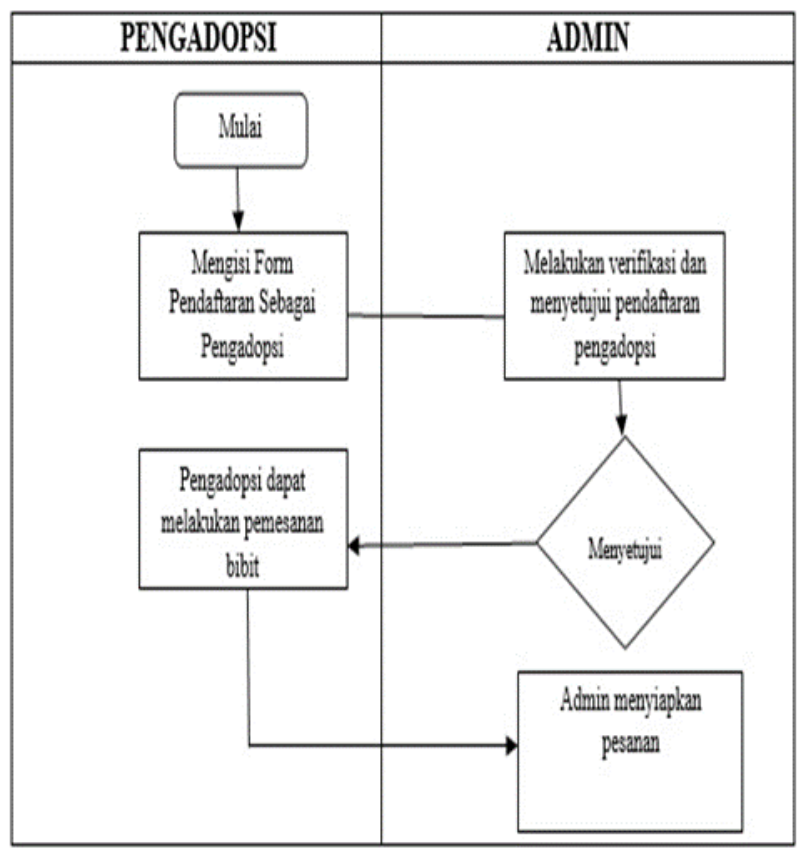

Gambar 1. Sistem yang Diusulkan

Unified Modeling Language (UML) merupakan salah satu alat yang sering dipakai dalam pengembangan sistem berorientasi objek. Hal ini dikarenakan dalam UML tersedia bahasa pemodelan visual yang memudahkan pengembang sistem untuk mencapai tujuan mereka dalam bentuk standar, dapat dipahami, serta terdapat efektif mekanisme untuk berbagi dan menginformasikan desain tersebut ke orang lain (Waspodo, 2015). Use Case Diagram adalah UML (Unified Modeling Language) model diagram yang digunakan untuk menggambarkan yang diharapkan persetujuan fungsional suatu sistem (Prihandi, 2020). Use case diagram menjelaskan peran admin dalam mengakses data bibit dan laporan sedangkan mitra hanya dapat mengakses data bibit. Selain itu pengadopsi dapat melihat perkembangan bibit. 


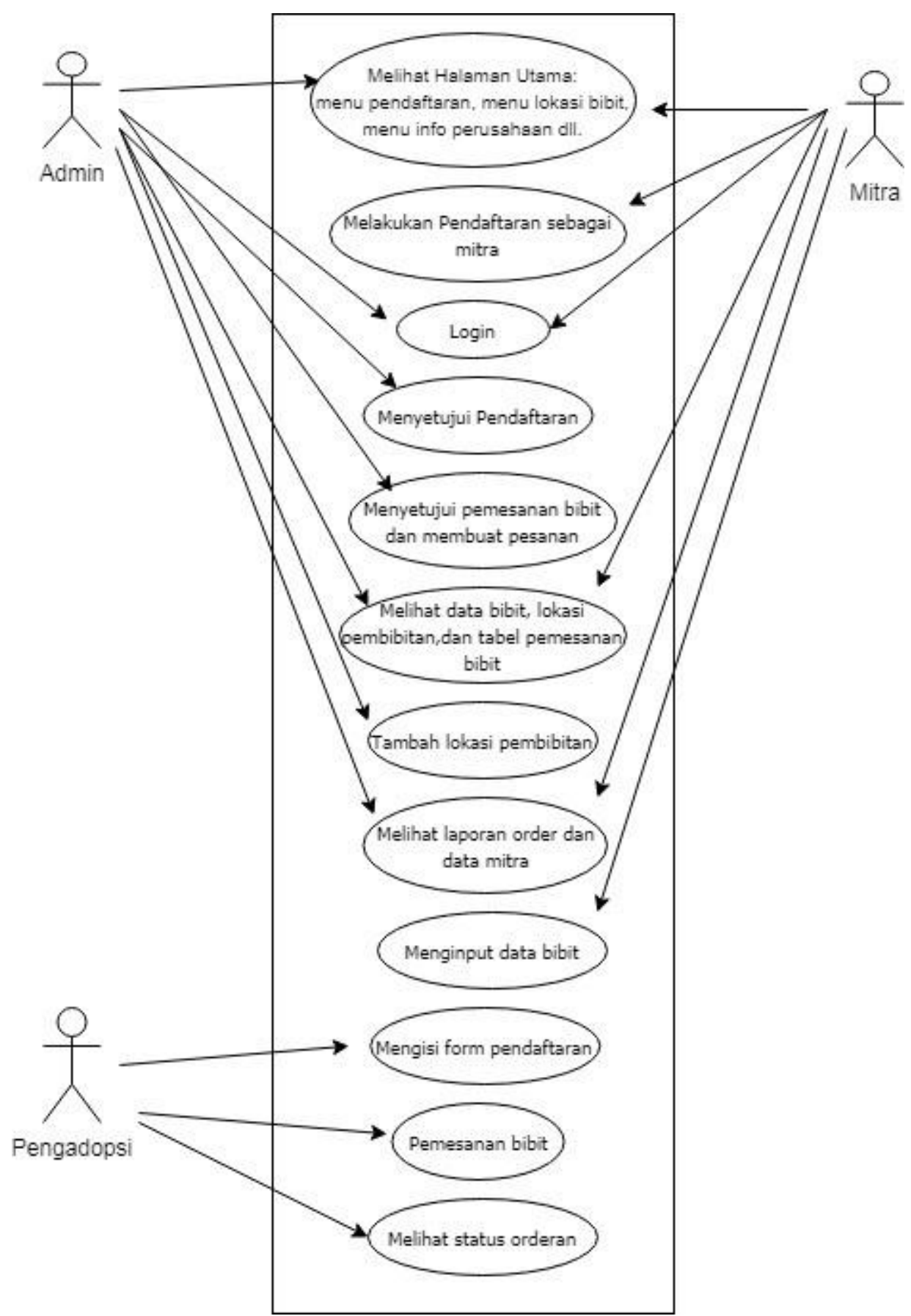

Gambar 2. Use Case Diagram

Activity diagram menjelaskan tentang langkah-langkah cara kerja didalam sistem yang dirancang, sehingga masing-masing alur kerja dimulai dari awal, kondisi yang bisa terjadi pada saat eksekusi program sampe akhir sistem itu berjalan. Berikut merupakan activity diagram perancangan sistem pembibitan. 


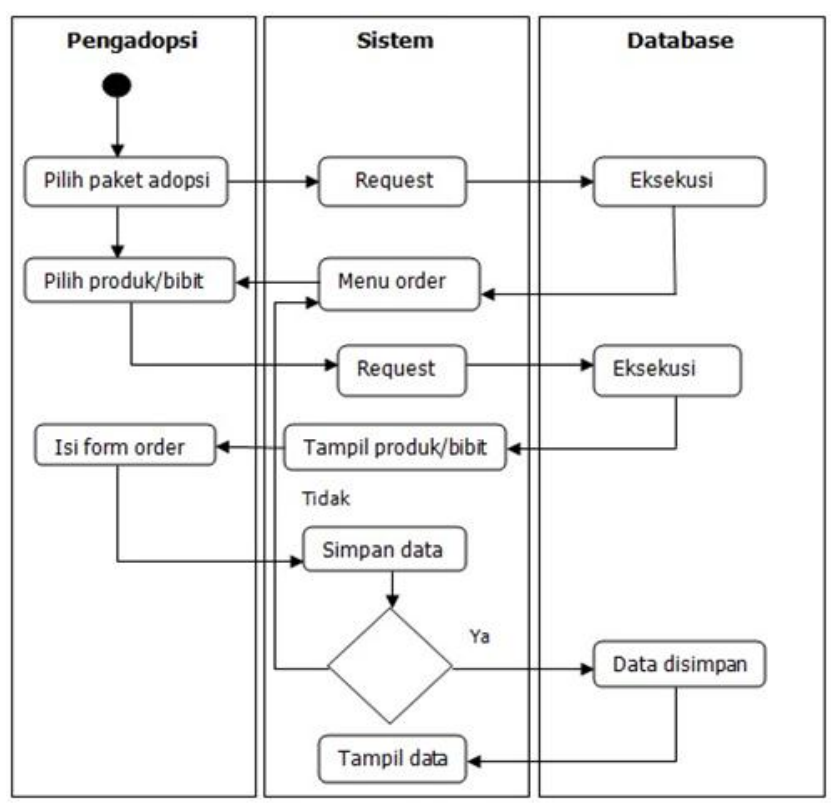

Gambar 3. Activity Diagram

Class diagram merupakan gambaran yang berisi tentang class, atribut yang saling berhubungan satu sama lain antar tabel, metode atapun operasi yang berguna untuk dibangunnya sebuah sistem dan kunci utama berjalannya sebuah database.

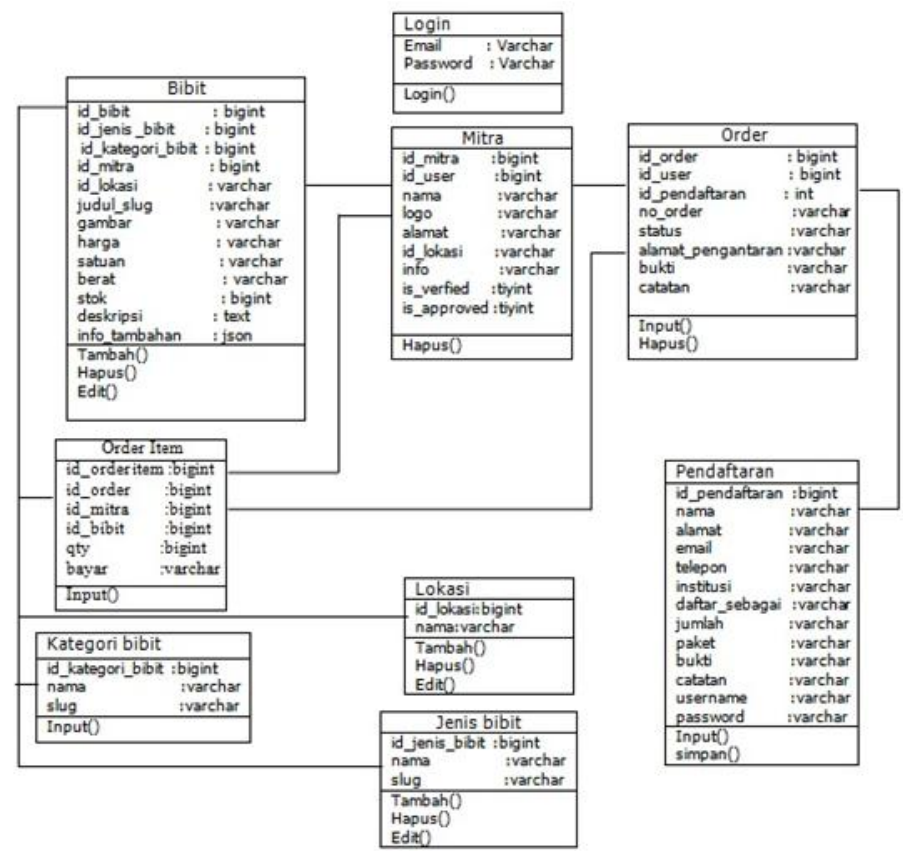

Gambar 4. Class Diagram

Pada Sequence Diagram, alur dan tahap dari setiap proses yang terjadi pada sistem akan digambarkan (Turnip, 2020). Sequence diagram pemesanan menggambarkan admin dengan aplikasi dan database dalam melakukan pemesanan. 


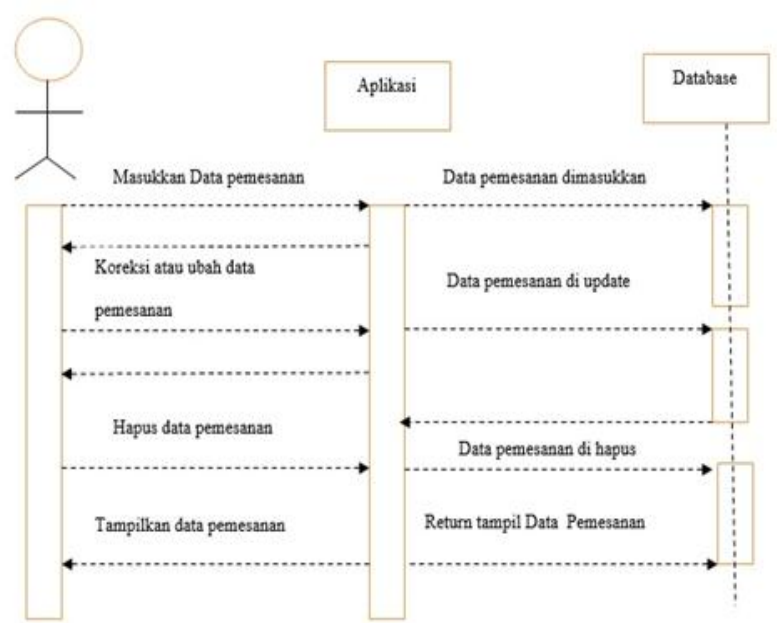

Gambar 5 Sequence Diagram Pemesanan

\section{HASIL DAN PEMBAHASAN}

Pada hasil penelitian ini dibangun sebuah sistem pembibitan berbasis website. Sistem pembibitan ini berfungsi memberikan kemudahan kepada para pengadopsi untuk melakukan pemesanan bibit yang diinginkan dengan cepat dan akurat. Mitra sebagai penyedia bibit lebih mudah bergabung dan melakukan transaksi dengan admin perusahaan.

Gambar 6 menunjukkan bahwa di Homepage yang muncul pertama setelah mengakses situs atau alamat web menampilkan form pendaftaran, pembibitan, Tentang kami (perusahaan), kontak, login/ masuk, daftar mitra, paket adopsi dan katalog bibit

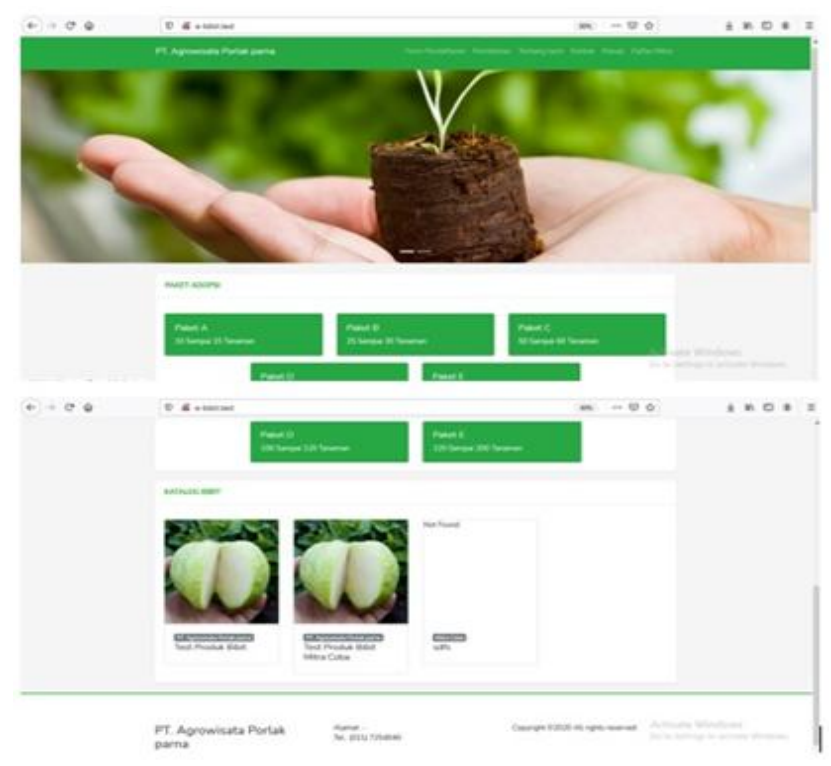

\section{Gambar 6. Halaman utama}

Pengadopsi bisa melakukan pendaftaran untuk membeli bibit, setelah mendaftar data tersebut tersimpan dan diproses oleh admin, kemudian bibit dikirim ke lokasi yang diminta oleh pengadopsi. Pembibitan berisi lokasi dan menampilkan data bibit yang ada di lokasi tersebut. Login berfungsi untuk pengguna agar bisa masuk kedalam sistem dengan memasukkan alamat email dan password, namun sistem ini hanya bisa diakses oleh dua 
pengguna saja yaitu admin pengelola data bibit dan mitra sebagai penyedia bibit. Daftar mitra adalah form daftar untuk mitra yang ingin bergabung ke perusahaan sebagai penyedia bibit, namun harus menunggu konfirmasi dari admin perusahaan agar bisa login dan mengelola data bibit. Katalog bibit merupakan tampilan gambar dan nama bibit yang tersedia di perusahaan. Di homepage juga menjelaskan secara singkat tentang PT. Agrowisata Porlak Parna dan terdapat kontak dan email yang bisa dihubungi bila terdapat masalah atau kendala.

Gambar 7 menunjukkan bahwa dashboard admin menampilkan data bibit, pertumbuhan bibit, lokasi pembibitan, mitra pembibitan, pemesanan bibit, jenis bibit, laporan data mitra serta laporan order. Pemesanan bibit berfungsi untuk membuat pesanan sesuai dengan permintaan pengadopsi. Setelah pesanan diproses admin, maka mitra akan mengirim bibit ke lokasi tujuan namun sebelumnya admin telah melakukan transaksi kepada mitra dan membayarnya. Laporan bisa di gunakan untuk kepentingan perusahaan.

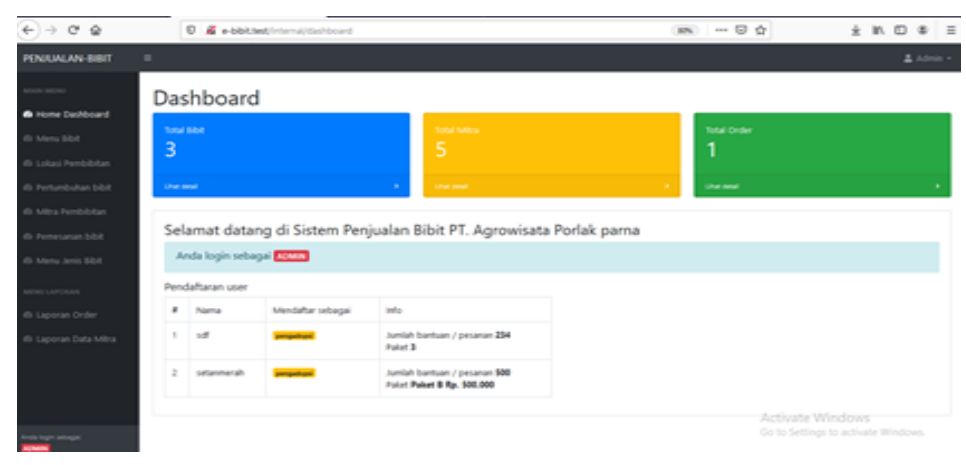

Gambar 7. Dashboard Admin

Gambar 8 menunjukkan bahwa Dashboard mitra menampilkan menu data bibit, transaksi pesanan dan pertumbuhan bibit. Menu data bibit berfungsi untuk menambahkan data bibit. Transaksi pesanan berfungsi untuk melihat pesanan bibit. Pertumbuhan bibit berisi lokasi dan nama bibit yang ada di tempat tersebut.

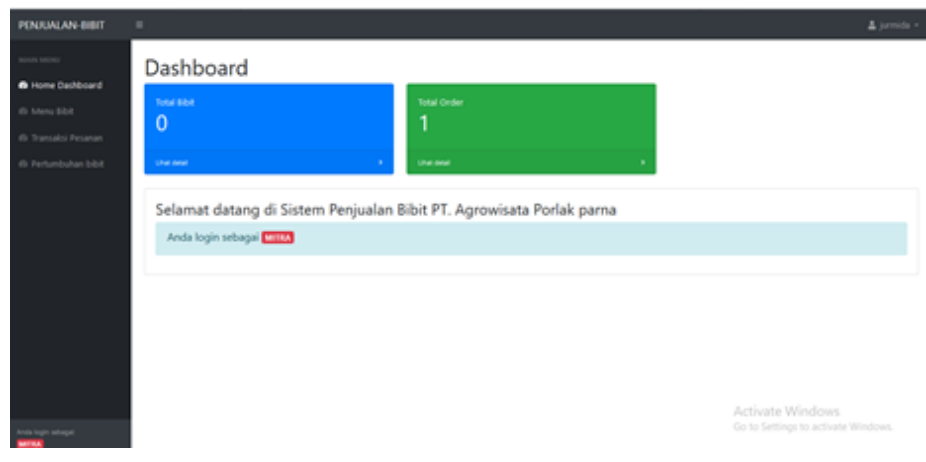

Gambar 8. Dashboard Mitra

Gambar 9 menunjukkan bahwa login terdiri dari alamat email dan password. Login berfungsi untuk masuk kedalam halaman dashboard yang hanya bisa di lakukan oleh mitra dan admin. 


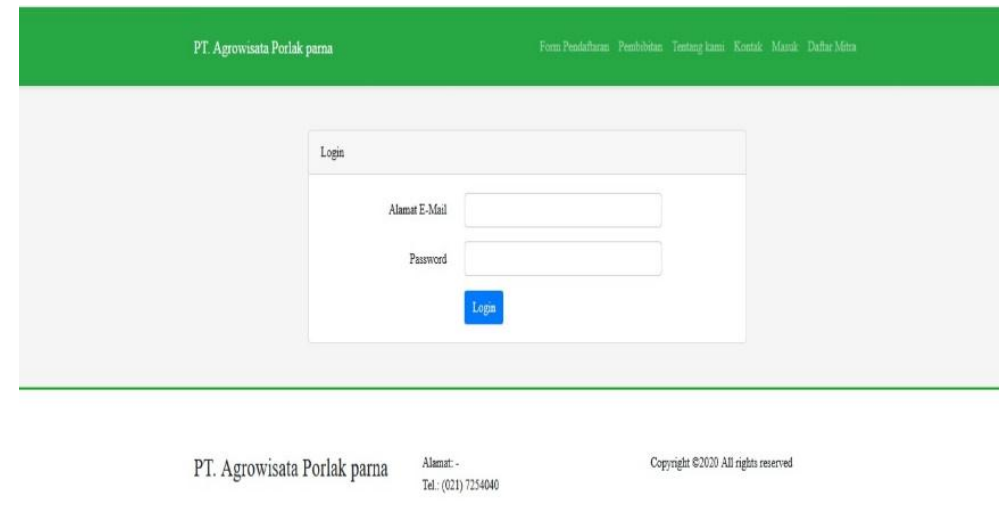

\section{Gambar 9. Login}

Gambar 10 menunjukkan bahwa form pendaftaran pengadopsi terdiri dari nama, alamat, email, telepon, institusi, jenis bibit, paket, jumlah, bukti, catatan, username, password. Form pendaftaran pengadopsi berfungsi ketika melakukan pengadopsian bibit, karena form tersebut akan masuk ke daftar pemesanan adopsi bibit ke dalam dashboard admin.

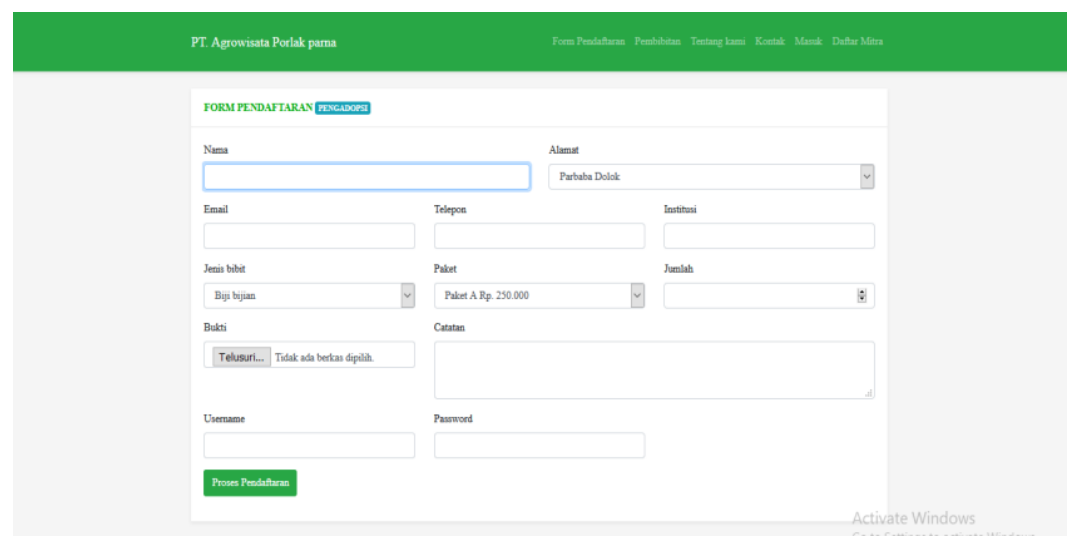

Gambar 10. Form Pendaftaran Pengadopsi

\section{KESIMPULAN}

Dengan adanya aplikasi ini perusahaan dengan mudah mengelola menyimpan dan membuat laporan data bibit dan mempermudah melakukan transaksi dengan mitra pembibit. Pengadopsi dengan mudah melakukan adopsi bibit karena dapat mengakses sistem kapanpun asal terhubung ke internet. Sistem Informasi pembibitan membantu meringankan pekerjaan pegawai dan meningkatkan kinerja yang baik terhadap PT. Agrowisata Porlak Parna.

\section{DAFTAR RUJUKAN}

Turnip, M., Novriyanti, D., N.K, M., \& Sitanggang, D. (2018). Aplikasi Perhitungan Angka Kredit Jabatan Fungsional Dosen berbasis Web menggunakan Model Waterfall. Jurnal Sistem Informasi Kaputama, 2(1), 37-46. 
Ziraba A and Okolo C (2018) The Impact of Information Technology (IT) Policies and Strategies to Organization's Competitive Advantage, V421249 pp. 22-25.

Pamoragung, A., Suryadi, K., \& Ramdhani, M. A. (2006). Enhancing the Implementation of eGovernment in Indonesia Through the HighQuality of Virtual Community and Knowledge Portal. 6th European Conference on e-Government, (pp. 341-347). Marburg: Academic Conferences Limited..

Ramdhani, M. A. (2013). Metodologi Penelitian untuk Riset Teknologi Informasi. Bandung: UIN Sunan Gunung Djati Bandung.

Rusli, Nurdin Noni, Nasrul Ihsan \& Ansari Saleh Ahmar, (2018). The Development of Research Management Information System Based on Web at Universitas Negeri Makassar, Indonesia. 2nd International Conference on Statistics, Mathematics, Teaching, and Research.

Loveri, T. (2007). Sistem Informasi Penyaluran Benih Dinas pertanian Tanaman Pangan Holtikutura Kabupaten Pasaman barat. Jurnal Ilmu Komputer, 6(1), 33-39.

Sapnado Galih (2020). Sistem Informasi Penjualan Bibit Tanaman Berbasis Web Menggunakan QRCODE di Toko Lana Sumberan Salaman. Eprints Repository Software, 2-4.

Dennis A, Wixom B H and Tegarden D (2015). Systems analysis and design: An objectoriented approach with UML. 2015.

Nabil Mohammed Ali Munassar and A. Govardhan (2010), "A Comparison Between Five Models Of Software Engineering", IJCSI International Journal of Computer Science Issues, $7(5), 94-101$.

Bahattab Abdullah and Alshamrani (2015). "A Comparison Between Three SDLC Models Waterfall Model, Spiral Model, and Incremental/Iterative Model". International Journal of Computer Science Issues, 12(1), 106.

Hariyanto, D., \& Meidiany, T. (2018). Sistem Informasi Akademik Sekolah Berbasis Website (Studi Kasus: SMK 11 Maret Jakarta). Jurnal Swabumi, 6(1), 98-103.

Susanti, Melan. (2016). Perancangan Sistem Informasi Akademik Berbasis Web Pada Smk Pasar Minggu Jakarta. Jakarta: STMIK Nusa Mandiri.

Muntihana, Vimila.(2017). Analisis Dan Perancangan Sistem Informasi Berbasis Web Dan Android Pada Klinik Gigi Lisda Medica Di Kabupaten Bulukumba Sulawesi Selatan. Makassar: Universitas Islam Negeri (UIN) Alauddin Makassar. 
Udi, Firmansyah, Yoki., (2018) "Penerapan Metode SDLC Waterfall Dalam Pembuatan Sistem Informasi Akademik Berbasis Web Studi Kasus Pondok Pesantren Al-Habi Sholeh Kabupaten Kubu Raya, Kalimantan Barat". Jurnal Khatulistiwa.

Risdiyansyah Deni, Purwaningtias, Deasy., dkk. (2018) "Penerapan Metode SDLC Waterfall Dalam Perancangan Sistem Informasi Administrasi Keuangan Berbasis Desktop". Jurnal Khatulistiwa Informatika, VI(2).

Dwi Wijaya Y, Wardah Astuti M. (2019) Sistem Informasi Penjualan Tiket Wisata Berbasis Web Menggunakan Metode Waterfall. Seminar Nasional Teknologi Informasi dan Komunikasi. 274.

Waspodo. Bayu, dkk. (2015). "Sistem Informasi Pelayanan Izin Mendirikan Bangunan Dan Peruntukan Penggunaan Tanah Pada Badan Penanaman Modal Dan Pelayanan Perizinan Kabupaten Sumedang". Jurnal Sistem Informasi, $8(2)$. Jakarta: Universitas Islam Negeri Syarif Hidayatullah.

Prihandi ifan, Roby Riyansyah.(2020). "Analysis and Design of Application Information System Website-Based Counseling Guide (Case Study: State Vocational School, 43 Jakarta)". International Journal of Scientific Engineering and Science, 4(2), 15-19.

Turnip Mardi, Bunawolo Methina, Br.Tarigan, V., E., Simbolon, N., Hulu Yosefa.(2020) " Aplikasi Sistem Informasi Manajemen Sekolah Terintegrasi dengan Pendekatan Rational Unified Process". Jurnal Ilmu Komputer dan Sistem Informasi, 3(2), 11-17. 